\title{
A importância do Atlas linguístico do Brasil para o ensino de português
}

\section{The importance of the Brazilian Linguistic Atlas for Portuguese teaching}

\author{
Josane Moreira de Oliveira ${ }^{1}$ \\ Marcela Moura Torres Paim ${ }^{2}$ \\ Silvana Soares Costa Ribeiro ${ }^{3}$
}

Resumo: Este artigo trata da importância dos atlas linguísticos para o ensino, destacando a publicação do At/as linguístico do Brasil, que objetiva oferecer subsídios para o aprimoramento do ensino/aprendizagem de língua portuguesa e para uma melhor interpretação do caráter multidialetal do Brasil, além de proporcionar aos interessados, sobretudo aos professores, nos estudos linguísticos um considerável volume de dados que permita aprofundar o conhecimento da realidade linguística do português brasileiro, refletindo sobre as variantes de que se reveste a nossa língua, bem como encontrar meios de, sem desprestigiar os seus dialetos de origem, levar os estudantes ao domínio de uma variedade tida como culta. Assim, discute-se a significativa contribuição dessa obra para o conhecimento da realidade linguística do português do Brasil, visto que $o$ atlas pode otimizar e motivar atividades em sala de aula, podendo também ser explorado nas demais disciplinas do currículo escolar.

Palavras-chave: Variação linguística; Ensino de Língua Portuguesa; Atlas linguísticos.

Abstract: This article discusses the importance of the linguistic atlases for teaching, highlighting the publication of the Brazilian Linguistic Atlas, that aims to offer subsidies for the improvement of Portuguese teaching / learning and for a better interpretation of the multidialectal character of Brazil, as well as to provide those interested, and teachers, in linguistic studies a considerable amount of data that allows to deepen their knowledge of the linguistic reality of Brazilian Portuguese, reflecting on the variants of our language, as well as finding ways to, without discrediting their dialects of origin, to bring students into the default language domain. Thus, it discusses the significant contribution of this work to the knowledge of the linguistic reality of Brazilian Portuguese, since the atlas can optimize and motivate activities in the classroom, and can also be explored in the other disciplines of the school curriculum.

Keywords: Linguistic variation; Portuguese teaching; Linguistic atlases.

\footnotetext{
1 Professora de Língua Portuguesa da Universidade Estadual de Feira de Santana. E-mail: josanemoreira@hotmail.com.

2 Professora de Língua Portuguesa da Universidade Federal da Bahia e Bolsista PNPD/CAPES, supervisionada pela Professora Josane Moreira de Oliveira na Universidade Estadual de Feira de Santana. E-mail: mmtpaim@ufba.br.
}

${ }^{3}$ Professora de Língua Portuguesa da Universidade Federal da Bahia. E-mail: silvanar@ufba.br. 


\section{Para que servem os atlas linguísticos?}

No uso cotidiano da língua, as pessoas produzem, constante e conscientemente, construções precisas para que exista o mútuo entendimento e para que se cumpram os objetivos da interação comunicativa. É exatamente esse esforço que instala na enunciação mecanismos que deixam explícita a presença da diversidade linguística.

No âmbito da Linguística, a ciência que se dedica prioritariamente à variação espacial chama-se Dialetologia, que, conforme Cardoso (2010, p. 15), é definida como a área dos estudos linguísticos que se propõe a identificar, descrever e sistematizar os distintos usos em que uma língua varia, segundo os aspectos geográficos, sociais e temporais.

Na contemporaneidade, a Dialetologia investiga não só as variações geográficas dos dialetos e falares de uma localidade específica, numa perspectiva monodimensional, mas também as variações sociais, nelas inseridas as variações diageracionais, diassexuais e diastráticas, delimitadoras de um grupo que imprime à sua linguagem marcas de sua cultura local e regional, bem como as variações estilísticas.

Sobre essa nova configuração dialetológica, Thun (1998, p. 707) aclara que a Dialetologia pluridimensional se dedica aos estudos dos fatos de microcosmos (detalhes fônicos, semânticos, sintáticos etc.) em escala macrocósmica (em toda uma zona) e os produtos dessas investigações são apresentados em mapas específicos de forma adequada. Dessa forma, a pluridimensionalidade reflete as questões do fazer linguístico de maneira ampla, mantendo a observação prioritária no fator espacial, mas adicionando outros aspectos sociais, como sexo, faixa etária, escolaridade e estilo de fala, nas análises dos dados.

Uma das maneiras de se pesquisar a língua na perspectiva dialetológica é através dos atlas linguísticos, que se definem como conjuntos de mapas, ou cartas linguísticas, nos quais se encontram registradas as variações fonéticas, léxico-semânticas e morfossintáticas, presentes em cada uma das regiões, sub-regiões e localidades onde essa diversidade de usos acontece. Por isso, os atlas, que podem representar a variação linguística, seja ela espacial, eminentemente, seja ela social, são obras ricas e produto de um trabalho intenso dos seus autores.

Como expõem Ferreira et al. (1996, p. 484), um atlas linguístico apresenta, de maneira conjunta, mapas territoriais, os quais localizam as realizações dos fatos linguísticos em estudo (fonético, lexical, morfológico ou sintático), registrando as respectivas variações espaciais. Nesse sentido, o domínio diatópico de amplitude de um atlas linguístico pode ser planejado por critérios de diferentes naturezas, permitindo o fornecimento de um panorama espacial de fenômenos linguísticos, além de possibilitar a delimitação da sua extensão. Vale salientar que os atlas não são um conglomerado de dados linguísticos, mas, segundo Ferreira et al. (1996, p. 484), proporcionam o isolamento e o estudo de áreas dialetais, configurando-se como um instrumento de trabalho indispensável para a Dialetologia e para a História da Língua.

A partir dessas considerações preliminares, observa-se que um atlas linguístico é fundamental para os estudos da língua, pois, além de documentar a memória sociolinguística de um povo, ou seja, a história da língua, é também um poderoso instrumento para as políticas linguísticas, sobretudo no que diz respeito às políticas de ensino. 


\section{Tudo é diverso no universo}

A Geografia Linguística, no Brasil, surge com um pensamento inicial: a produção de um atlas linguístico geral do Brasil no tocante à língua portuguesa. Isso é o que se firma no Decreto $n^{\circ} 30.643$, de 20 de março de 1952, que assentava, no seu Art. 30, como principal finalidade da Comissão de Filologia da Casa de Rui Barbosa, a elaboração do atlas linguístico do Brasil.

Tal determinação foi regulamentada pela Portaria n. ${ }^{0}$ 536, de 26 de maio do mesmo ano, a qual, ao baixar instruções relacionadas à execução do decreto de criação do Centro de Pesquisas Casa de Rui Barbosa, estabeleceu, como finalidade principal, entre as pesquisas a serem planejadas, a própria elaboração do atlas linguístico brasileiro. Contudo as circunstâncias de âmbito acadêmico, social e histórico fizeram com que se abdicasse, naquele momento, da proposta de fazer um atlas nacional e se passasse a enveredar por empreendimentos voltados para a produção de atlas regionais.

Entra no cenário da Dialetologia do Brasil, então, um novo capítulo composto pela publicação das Bases para a elaboração do atlas lingüístico do Brasil em dois volumes (1958 e 1961), de Antenor Nascentes; pela investida na criação de uma mentalidade dialetológica por Serafim da Silva Neto; e pela defesa da realização de atlas regionais, reconhecendo a impossibilidade, naquele momento, de produção de um atlas nacional, por Celso Cunha.

A ideia do atlas linguístico do Brasil foi retomada por ocasião do Seminário Nacional Caminhos e Perspectivas para a Geolinguística no Brasil, realizado em Salvador, na Universidade Federal da Bahia, em novembro de 1996, com a participação de dialetólogos brasileiros e do Diretor do Atlas Linguistique Roman (ALiR), Prof. Michel Contini (Grenoble). Naquela ocasião, foi criado um Comitê Nacional, integrado pelos autores dos cinco atlas linguísticos regionais já publicados e por um representante dos atlas em andamento. Foram eles: os Professores Suzana Alice Marcelino da Silva Cardoso, que presidiu o Comitê até 2 de maio de 2018, e Jacyra Andrade Mota (ambas da Universidade Federal da Bahia), coautoras do Atlas linguístico de Sergipe; Maria do Socorro Silva de Aragão (Universidade Federal da Paraíba), coautora do Atlas linguístico da Paraíba; Mário Roberto Lobuglio Zágari (Universidade Federal de Juiz de Fora), coautor do Esboço de um atlas linguístico de Minas Gerais, Vanderci de Andrade Aguilera (Universidade Estadual de Londrina), autora do Atlas linguístico do Paraná; e Walter Koch (Universidade Federal do Rio Grande do Sul), este último representando os atlas em andamento ${ }^{4}$.

Integram o Projeto Atlas Linguístico do Brasil (ALiB) várias instituições brasileiras, articuladas mediante convênio que entre si firmaram a Universidade Federal da Bahia (UFBA), a Universidade Federal do Ceará (UFC), a Fundação Universidade do Rio Grande do Norte (UFRN), a Universidade Federal do Rio Grande do Sul (UFRGS), a Universidade Estadual de Londrina (UEL), a Universidade Federal do Mato Grosso do Sul (UFMS), a Universidade Federal da Paraíba (UFPB), a Universidade Federal do Maranhão (UFMA), a Universidade Estadual do Ceará (UECE), o Centro Federal de Educação Tecnológica da Paraíba (atual IFPB), a Universidade Federal do Pará (UFPA), a Universidade Federal do Piauí (UFPI) e a Universidade Federal de Santa Catarina (UFSC).

\footnotetext{
${ }^{4}$ Atualmente, o Comitê Nacional do Projeto ALiB é constituído pela Diretora Presidente - Jacyra Andrade Mota (UFBA), pela Diretora Executiva - Silvana Soares Costa Ribeiro (UFBA) e pelos Diretores Científicos: Abdelhak Razky (UFPA); Aparecida Negri Isquerdo (UFMS); Conceição Maria de Araújo (UFMA); Fabiane Cristina Altino (UEL); Felício Wessling Margotti (UFSC); Marcela Moura Torres Paim (UFBA); Maria do Socorro Silva de Aragão (UFPB/UFC); Marilúcia Barros de Oliveira (UFPA); Regiane Coelho Pereira Reis (UFMS); Valter Romano (UFLavras) e Vanderci de Andrade Aguilera (UEL).
} 
O Projeto ALiB fundamenta-se nos princípios gerais da Geolinguística contemporânea, priorizando a variação espacial ou diatópica e atento às implicações de natureza social que não se podem, no estudo da língua, deixar de considerar. Assim, o Projeto ALiB objetiva descrever o português falado no Brasil com base em dados coletados em 250 pontos, representativos de todas as regiões, e recolhidos, in loco, a 1.100 informantes, distribuídos equitativamente por duas faixas etárias - 18 a 30 anos e 50 a 65 anos -, pelos dois sexos e, nas capitais de Estado, em número de 25 (as capitais Palmas, Estado de Tocantins, e Brasília, Distrito Federal, se excluem por questões metodológicas em virtude de serem cidades recémcriadas), por dois níveis de escolaridade - fundamental e universitário -, ficando os demais pontos da rede com apenas informantes do nível fundamental.

Esse caráter de que se reveste o Projeto ALiB tem duas evidentes implicações: por um lado, inspira e fundamenta a sua concepção na pluralidade do conhecimento; por outro, permite que, dos resultados que venha a oferecer, se beneficie amplo espectro das ciências na atualidade.

Em 2014, os Volumes 1 (Introdução) e 2 (Cartas linguísticas) do Atlas linguístico do Brasil foram publicados como frutos do trabalho desenvolvido pelo Projeto ALiB, que objetiva documentar, descrever e interpretar a realidade do português brasileiro, tendo, exatamente por esse caráter, uma evidente interface com diferentes ramos do conhecimento organizado, decorrente do fato de que a história de uma língua é a história do próprio povo que a fala.

Atualmente, prepara-se o volume 3, que contempla estudos sobre as cartas publicadas no volume 2, apresentado a análise dos dados cartografados. Dois outros volumes encontram-se em fase de andamento, os volumes 4 e 5 , voltados ainda para os materiais coletados nas capitais de estado. Os volumes 6 e 7, já programados, iniciam a abordagem dos resultados obtidos na pesquisa das cidades que integram a rede de pontos no interior dos estados.

A publicação do Atlas linguístico do Brasil vem preencher uma lacuna nos estudos dialetais brasileiros, qual seja, a de apresentar, de maneira comparativa, dados sobre o português brasileiro considerado na sua diversidade espacial, portanto diatópica, e observadas as variáveis sociolinguísticas que atuam na língua, de que resulta a diversidade de usos nos planos diageracional, diastrático, diassexual e/ou diafásico.

Paralelamente, desenvolvem-se dois subprojetos que exploram os materiais de campo direcionados para duas vertentes: a produção de um dicionário regional (Projeto DDB) e o estudo da fraseologia (Projeto Valextra).

Pensando na necessidade de uma maior difusão e no acesso ao conhecimento da realidade linguística do Brasil, desenvolve-se no Projeto ALiB o Projeto Dicionário Dialetal Brasileiro (Projeto DDB) que envolve especialistas da área da dialetologia e da lexicografia e das ciências da informação, do Brasil e da França -, com o intuito de elaborar um dicionário que possa assegurar a difusão mais ampla do conhecimento da realidade linguística brasileira no âmbito dos estudos lexicográficos.

O referido projeto, idealizado e coordenado por Américo Venâncio Lopes Machado Filho (UFBA), advém, inicialmente, de um acordo de cooperação entre a Universidade Federal da Bahia e a Université de Paris 13 a partir da participação das equipes do LDI (Lexiques, Dictionnaires, Informatique, Laboratório da Université de Paris 13) e do ALiB no Programa CAPES/COFECUB, envolvendo, assim, uma equipe multidisciplinar e interinstitucional. 
O Projeto Valextra, coordenado por Marcela Moura Torres Paim (UFBA), consiste na cooperação do LDI (Lexiques, Dictionnaires, Informatique, Laboratório da Université de Paris 13), sob a direção do Prof. Dr. Salah Mejri, e da Universidade Federal da Bahia, através do Projeto CAPES/COFECUB 838/15, desenvolvido no período 2015-2018.

Com base nos recursos do ALiB e da lexicografia brasileira e com vistas à elaboração de um inventário dos pragmatemas e das variantes sociodialetais mais frequentes no português brasileiro com os respectivos equivalentes em francês, o referido projeto tem como objetivos específicos: (i) estabelecer uma base de dados colocacionais bilíngues francês/português brasileiro, com base em corpus textual; (ii) viabilizar soluções para as lacunas teóricas que se apresentarem; (iii) dimensionar a atuação do fenômeno da colocação na idiomaticidade de uma língua ou de suas variedades - como por exemplo, o português brasileiro em relação à lusofonia em geral; (iv) observar a relevância quantitativa e qualitativa de diversos tipos de variação no âmbito da Fraseologia.

Como é possível perceber, o Atlas linguístico do Brasil tem, pois, um significativo papel para o conhecimento, a divulgação e a reflexão sobre a língua portuguesa, podendo também contribuir para a elaboração de dicionários escolares, dando um salto da teoria à prática para que estudiosos da língua encontrem as formas de aprofundar a pesquisa e o ensino-aprendizagem da língua portuguesa, tendo em vista a variação linguística.

\section{O papel do Atlas linguístico do Brasil no ensino da língua portuguesa}

Descrever a realidade linguística de estados, regiões e do Brasil, no que tange à língua portuguesa, e oferecer aos estudiosos da língua portuguesa e das demais áreas dos estudos linguísticos, aos pesquisadores de áreas afins (história, antropologia, sociologia, entre outras) e aos pedagogos (gramáticos, autores de livros-texto para o ensino fundamental e médio, professores) subsídios para o aprimoramento do ensino/aprendizagem e para uma melhor interpretação do caráter multidialetal brasileiro são algumas das contribuições dos atlas linguísticos no ensino da língua.

Além desses benefícios, os atlas oferecem um significativo volume de dados, ampliando consideravelmente as informações hoje disponíveis aos interessados em estudos linguísticos, e, especialmente, aos estudiosos da língua portuguesa. Assim, os atlas dão subsídios para o aprimoramento do ensino/aprendizagem, com dados linguísticos que proporcionam a adequação de material didático à realidade linguística de cada região e o entendimento do caráter multidialetal do Brasil, contribuindo para o entendimento da língua portuguesa no Brasil como instrumento social de comunicação diversificado, possuidor de várias normas de uso, como se procura, a seguir, ilustrar, ainda que não de forma exaustiva, nos níveis fonético, morfossintático e lexical.

- Fonético - respondendo à indagação como: onde o brasileiro realiza a palatalização quando pronuncia palavras como tia, dia, noite ou tarde? 
Figura 1 - Carta F06 C 1 sobre as realizações palatais nas capitais

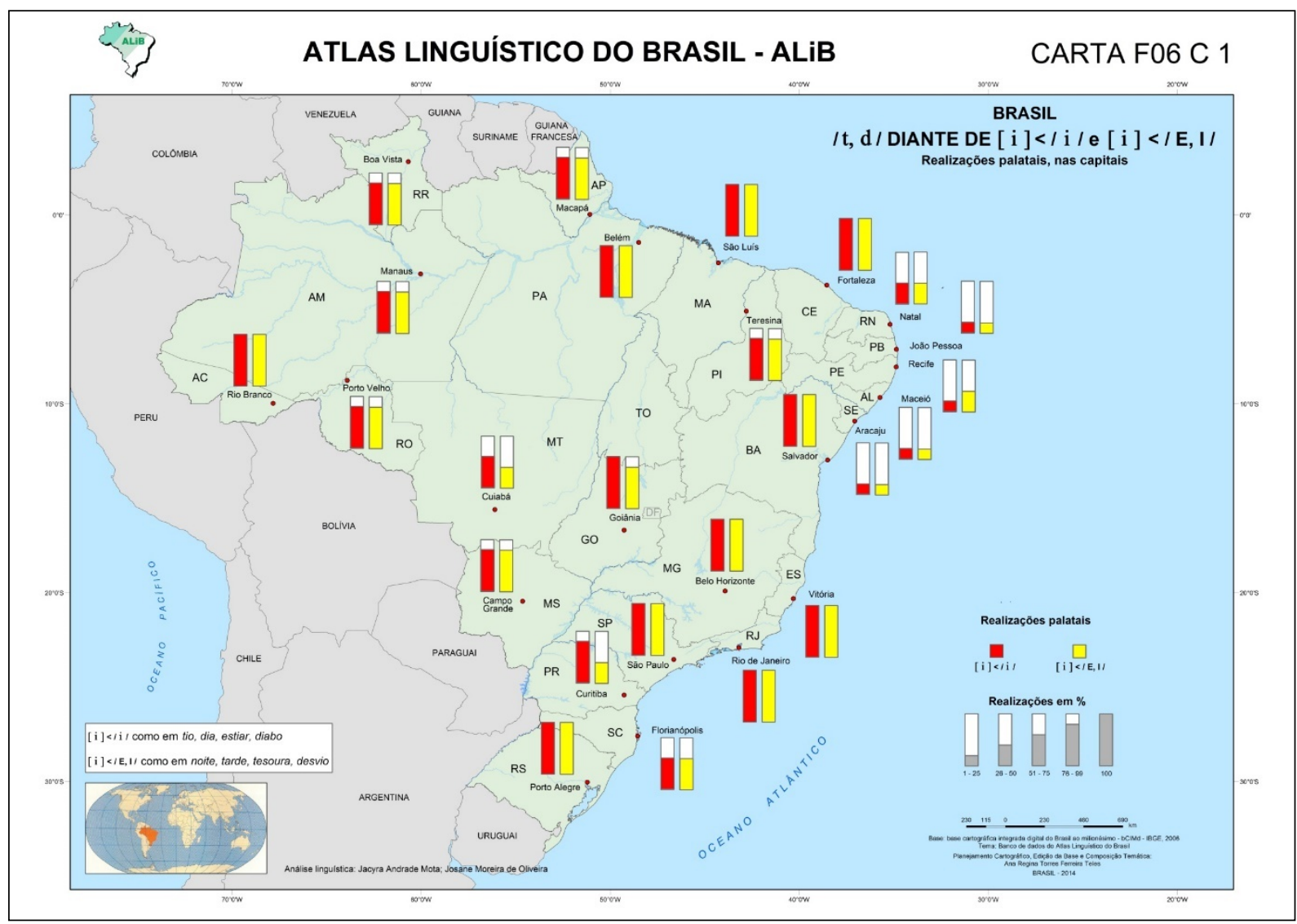

Fonte: Cardoso et al. (2014b, p. 123)

A partir da apresentação da carta, produzida a partir dos estudos linguísticos desenvolvidos por Oliveira e Mota (2014b), o professor pode discutir sobre as localidades brasileiras em que predomina a realização palatal ou "chiada" na pronúncia do /t/ e do /d/ diante da vogal [i]. Partindo desse debate, ratifica-se a importância dos estudos dialetais no sentido de que, por meio da documentação de dados linguísticos, em perspectiva horizontal, depreende-se o fato de a língua estar em constante variação.

Em atividades de sala de aula, o professor de português pode, a partir dessa carta, mostrar aos alunos que a pronúncia de /t/ e /d/ diante de [i] - seja como vogal fonológica (em palavras como tía, dia, $\underline{t i a r a}$, diabo) ou como vogal derivada ${ }^{5}$ (em palavras como téatro, depois, noite, tarde) - é variável no Brasil.

Na carta F06 C 1, em vermelho estão computadas as ocorrências de /t/ e /d/ diante de [i] vogal fonológica e em amarelo, as ocorrências de /t/ e /d/ diante de [i] vogal derivada. E pode-se ver que predomina nas capitais do Brasil a realização palatal dessas consoantes, com exceção das capitais nordestinas a seguir enumeradas: Natal (RN), João Pessoa (PB), Recife (PE), Maceió (AL) e Aracaju (SE). Cumpre notar também que em Florianópolis (SC) e em Cuiabá (MT) há muita variação na realização

${ }^{5}$ Considera-se vogal derivada a realização da vogal pretônica /E/ ou da vogal postônica /I/ como [i]. 
dessas consoantes. Já em Curitiba (PR), é interessante verificar que a palatalização predomina quando a vogal é fonológica, mas não quando a vogal é derivada.

Assim, esse material, ao ser apresentado em sala de aula, permite a visualização das diferentes formas de pronunciar essas consoantes e a discussão sobre a validade e, portanto, o respeito às variações linguísticas. Provavelmente, o professor terá em sala alunos provenientes de regiões que pronunciam diferentemente esses sons e/ou que conheçam pessoas que articulem diferentemente esses segmentos. Finalmente, o professor pode ressaltar que essa variação de /t/ e /d/ acontece diante de [i] mas não diante de outras vogais. E as explicações (históricas, geográficas, socioculturais) para essa variação dialetal serão disponibilizadas em artigo sobre esse tema a sair no volume 3 do Atlas linguístico do Brasil, que poderão ser alvo de discussão não só nas aulas de português mas também nas aulas de história e de geografia, ratificando a interdisciplinaridade que caracteriza um atlas linguístico na escola.

- Morfossintático - respondendo à indagação como: onde os brasileiros de nível fundamental ou universitário usam as palavras menos ou menas?

Figura 2: Carta M03E sobre a flexão de menos nas capitais

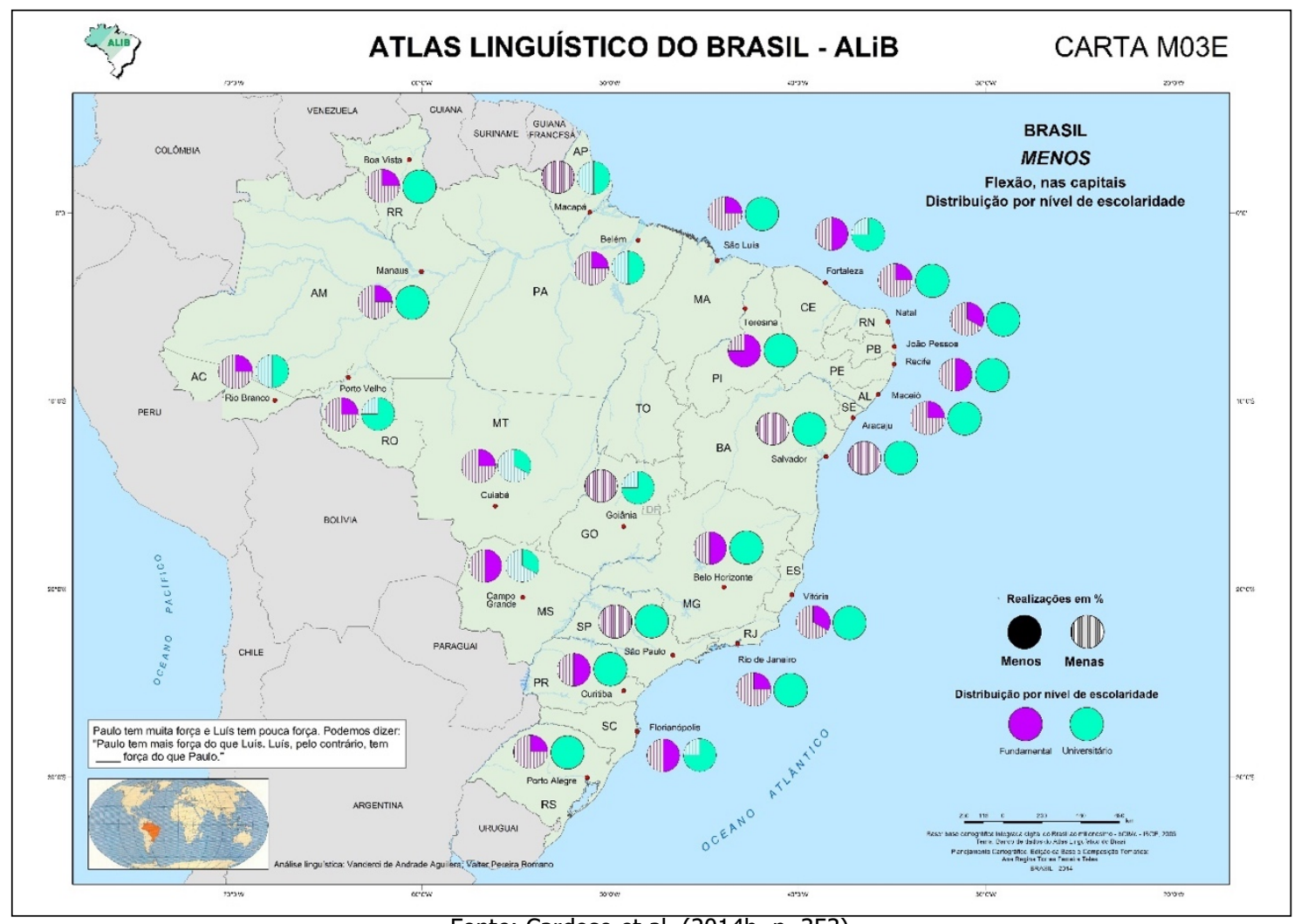

Fonte: Cardoso et al. (2014b, p. 353)

Por meio da carta diastrática, elaborada a partir dos estudos linguísticos desenvolvidos por Aguilera e Romano (2014b), que mostra a distribuição da alternância dos usos das formas menos e menas nas capitais brasileiras em relação aos informantes de nível fundamental e universitário, a atividade 
desenvolvida na escola poderá ser verificar onde predominam as variantes padrão e não-padrão nos dados dos falantes mais e menos escolarizados.

Isso permitirá perceber que em Cuiabá (MT) e Campo Grande (MS), por exemplo, os informantes de nível universitário completo utilizam predominantemente a forma menos. Já a forma menas é a mais usada pelos falantes de nível fundamental em todo o Brasil, com exceção de Fortaleza (CE), Recife (PE), Belo Horizonte (MG), Curitiba (PR), Florianópolis (SC) e Campo Grande (MS), em que essa forma atinge $50 \%$ dos dados, e de Teresina (PI), que apresenta $75 \%$ de menos.

Por meio dessa discussão, o estudante poderá perceber que quanto maior o nível de escolaridade do informante maior é o uso da forma não flexionada menos, como prevê a gramática normativa. Além disso, é possível que o professor incentive a atividade de pesquisa em dicionários e em gramáticas com o objetivo de instigar a discussão da origem e do uso do menos quanto à etimologia como advérbio e de abordar a presença de tratamento diferenciado no que diz respeito às classes gramaticais, que podem ser variáveis ou invariáveis em relação à flexão de gênero. Outro ponto que poderá ser destacado na aula de português é o valor social atribuído à forma menas, considerada estigmatizada mas cuja explicação se encontra na aplicação da regra de concordância nominal, neste caso fruto de um caso de hipercorreção.

- Lexical - comprando na loja bala, bombom, caramelo, confeito ou queimado, a depender de onde o falante se encontra.

Figura 3 - Carta L24 sobre as designações para bala nas capitais

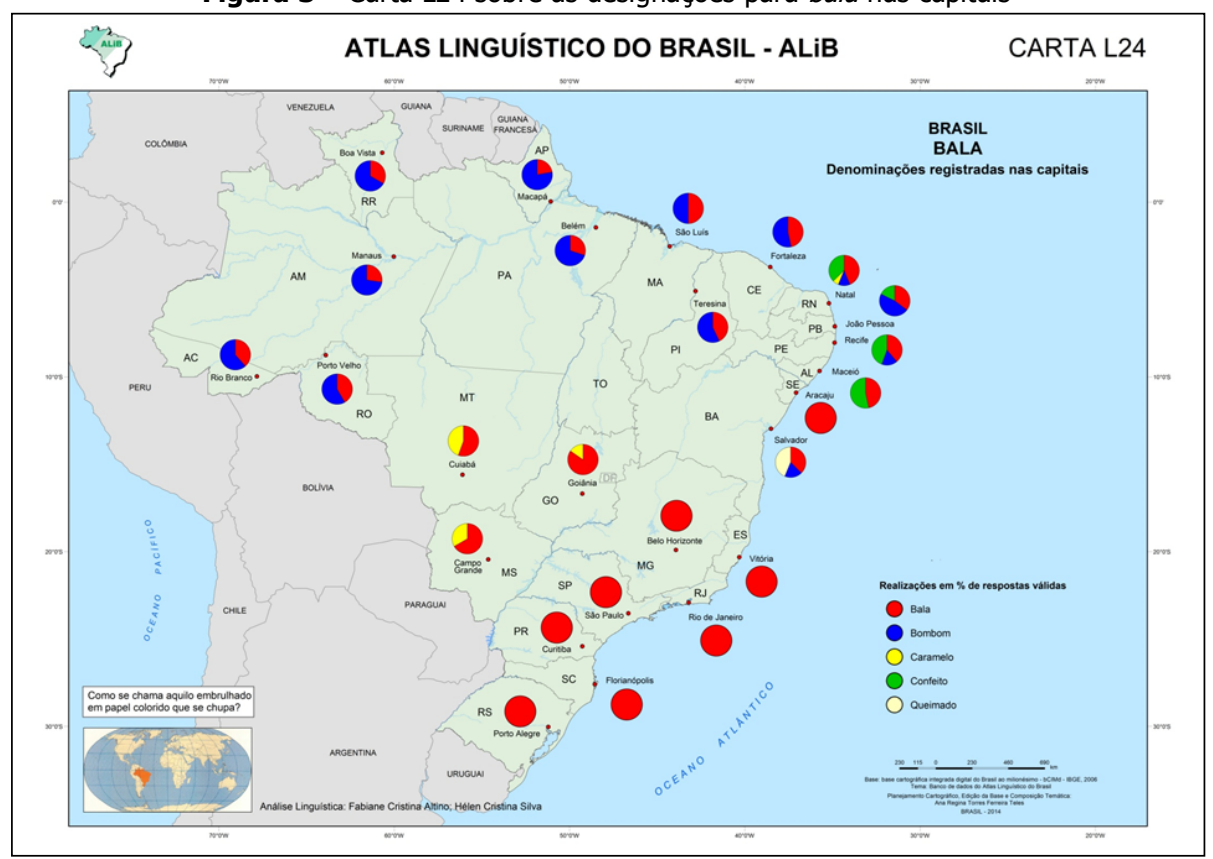

Fonte: Cardoso et al. (2014b, p. 327)

A carta sobre as denominações para bala nas capitais brasileiras, realizada por Altino e Silva (2014b), também pode servir como material didático para análise da variação linguística geográfica. Por meio da análise, os estudantes poderão ser levados a observar que a variante bala, considerada majoritária, é a mais produtiva no País. Um destaque a ser mencionado é o fato de na região Nordeste 
observar-se a convivência de bala com outras variantes, com exceção de Aracaju (SE), que apresenta categoricamente a forma bala. A variante bombom está presente nas capitais das regiões Norte e Nordeste do País, com exceção de Aracaju (SE). A variante caramelo concentra-se nas três capitais da região Centro-Oeste e na capital Natal (RN), localizada na região Nordeste. A denominação confeito está presente em quatro das nove capitais do Nordeste: Natal (RN), João Pessoa (PB), Recife (PE) e Maceió (AL). No que se refere à variante queimado, destaca-se a sua presença exclusivamente na cidade de Salvador (BA).

Além de proporcionar uma discussão que envolve a geografia e a diversidade linguística, é interessante também mencionar a possibilidade de refletir sobre os costumes alimentares. Sugere-se incentivar os alunos à consulta de dicionários no intuito de verificar se as variantes para "aquilo embrulhado em papel colorido que se chupa", presentes nas cartas, estão dicionarizadas e quais as acepções existentes.

Conforme é possível perceber, o Atlas linguístico do Brasil revela a fotografia da língua portuguesa, num dado momento e em localidades diferentes, otimizando as atividades em sala de aula, podendo também ser explorado nas demais disciplinas do currículo escolar. Nesse âmbito, também aponta as relações da língua com as distintas áreas do conhecimento, com as diferentes formas de se comportar, com o ser do homem. Afinal, com a sua própria língua, o homem se espacializa - é um soteropolitano ou um pernambucano -, comprando queimado ou confeito para chupar; ele se posiciona, do ponto de vista social, mostrando o estrato social em que se situa. Da mesma forma, ainda tomando como exemplo um falante soteropolitano e um pernambucano, pode-se perceber o uso variável de /t/ e /d/ diante da vogal [i], como exposto anteriormente.

Com todos esses contextos, os atlas linguísticos oportunizam descobertas sobre a língua, pois dão elementos importantes para o ensino-aprendizagem da língua equacionado à realidade de cada região, possibilitando, dessa forma, o reconhecimento do caráter linguístico de cada área e a sua vinculação ao estabelecimento de princípios metodológicos do ensino do vernáculo.

Assim, encontra-se na agenda de trabalho do Projeto ALiB a realização do Alibinho, atlas linguístico do Brasil para crianças, idealizado por Suzana Cardoso, no intuito de contribuir para: o ensino por meio de dados que apresentam a realidade espacial do domínio do português, evidenciando as distinções e semelhanças que se registram no território brasileiro; a discussão sobre a diversidade linguística, como fenômeno de todas as línguas; a diminuição de preconceitos relativos aos juízos de valores que denunciam noções equivocadas de "correto", "incorreto", "horroroso" e "lindo" e discriminações sociais com base na realidade da língua; a visualização de uma amostragem sobre como convivem diferenças e convergências, reconhecendo, porém, a validade da existência de um padrão culto necessário à comunicação oficial, à ministração do ensino, à efetivação do discurso formal e às opções de grupos de falantes; o fornecimento de elementos para a construção da história da língua portuguesa no Brasil, quer pela indicação dos caminhos seguidos, quer pela natureza das opções de mudança feitas, quer pelo estabelecimento de camadas caracterizadas linguística, social e geograficamente, quer, ainda, pela referência a resultados de contato com outras línguas ou à adoção de empréstimos linguísticos.

Diante de todos esses benefícios, verifica-se o papel de um atlas linguístico do Brasil, que também pode possibilitar a atualização de dicionários da língua portuguesa e a elaboração de uma gramática direcionada para a realidade do português brasileiro, aperfeiçoando o ensino, que é um agente 
de progresso e um dos grandes responsáveis pela qualidade da produção e pelo aperfeiçoamento de mão de obra qualificada de uma nação.

\section{Considerações finais}

As reflexões apresentadas mostram o caráter multidialetal do português brasileiro, evidenciando a importância do seu reconhecimento como maneiras de expressão da língua e a urgência de que, no momento do ensino formal, a pluralidade de usos seja levada para a sala de aula e discutida para a ampliação do conhecimento da língua portuguesa, para a formação da cidadania e para o respeito à diversidade.

Considerando o fato de que, no momento atual, a Dialetologia proporciona a reflexão sobre o ensino-aprendizagem da língua portuguesa, enfatizando a variação, acredita-se que o uso dos dados disponibilizados no Atlas linguístico do Brasil contribua para a diminuição dos estigmas e preconceitos linguísticos por meio da compreensão de língua como um instrumento complexo, rico e diversificado de comunicação, de expressão e, sobretudo, de socialização.

\section{Referências}

AGUILERA, V. de A. Atlas linguístico do Paraná. Curitiba: Imprensa Oficial do Estado, 1994.

AGUILERA, V. de A.; ROMANO, V. Cartas morfossintáticas. In: CARDOSO, S. et al. Atlas linguístico do Brasil, v. 2 (Cartas linguísticas). Londrina: EDUEL, 2014b, p. 351-355.

ALTINO, F. C.; SILVA, H. C.. Cartas semântico-lexicais. In: CARDOSO, S. et al. Atlas linguístico do Brasil, v. 2 (Cartas linguísticas). Londrina: EDUEL, 2014b, p. 327.

ARAgÃO, M. do S. S.; BEZERRA DE MENEZES, C. P. Atlas linguístico da Paraíba, v. 1 e 2. Brasília: UFPB/CNPq, Coordenação Editorial, 1984.

CARDOSO, S. Geolinguística: tradição e modernidade. São Paulo: Parábola, 2010.

CARDOSO, S. et al. Atlas linguístico do Brasil, v. 1 (Introdução). Londrina: EDUEL, 2014a.

CARDOSO, S. et al. Atlas linguístico do Brasil, v. 2 (Cartas linguísticas). Londrina: EDUEL, 2014b.

CONTINI, M. (Dir.). Atlas linguistique roman. Roma: Libreria dello Stato, v. 1, 1996; v. 2, 2001.

FERREIRA, C.; CARDOSO, Suzana. A dialectologia no Brasil. São Paulo: Contexto, 1994.

FERREIRA C.; MOTA J.; FREITAS, J.; ANDRADE, N.; CARDOSO, S.; ROLLEMBERG, V.; ROSSI, N. Atlas lingüístico de Sergipe. Salvador: UFBA-FUNDESC, 1987.

FERREIRA, M. B.; CARRILHO, E.; LOBO, M.; SARAMAGO, J.; CRUZ, L. S. Variação lingüística: perspectiva dialectológica. In: FARIA, I. H.; PEDRO, E. R.; DUARTE, I.; GOUVEIA, C. A. M. Introdução à lingüística geral e portuguesa. Lisboa: Editorial Caminho, S.A., 1996, p. 479-502.

NASCENTES, A. Bases para a elaboração do atlas lingüístico do Brasil. Rio de Janeiro: MEC; Casa de Rui Barbosa, v. 1, 1958; v. 2, 1961.

OLIVEIRA, J. Moreira; MOTA, J. A.. Cartas fonéticas. In: CARDOSO, S. et al. Atlas linguístico do Brasil, v. 2 (Cartas linguísticas). Londrina: EDUEL, 2014b, p. 123 a 129.

RIBEIRO, J. et al. Esboço de um atlas linguístico de Minas Gerais. Rio de Janeiro: Fundação Casa de Rui Barbosa; Universidade Federal de Juiz de Fora, 1977.

THUN, H. La geolingüística como linguística variacional general (com ejemplos del Atlas Linguístico Diatópico y Diastrático del Uruguay). CONGRESSO INTERNAZIONALE DI LINGUISTICA E FILOLOGIA ROMANZA, 21, 1995, Palermo. In: RUFINO, Gilvanni (Org.). Atti... Tübingen: Niemeyer, 1998, p. 701-729. 